\title{
Association and Expression Study of PRKCH Gene in a French Caucasian Population with Rheumatoid Arthritis
}

\author{
Vitor Hugo Teixeira • Laurent Jacq • Jeoiakim Moore • \\ Sandra Lasbleiz • Pascal Hilliquin • \\ Catarina Resende Oliveira • François Cornelis • \\ Elisabeth Petit-Teixeira
}

Received: 28 August 2007 / Accepted: 5 October 2007 / Published online: 24 October 2007

(C) Springer Science + Business Media, LLC 2007

\begin{abstract}
We study the association between three protein kinase C, eta gene polymorphisms $(+8134 \mathrm{C} / \mathrm{T}$, rs 912620 , rs959728), and susceptibility to rheumatoid arthritis. One hundred French Caucasian rheumatoid arthritis trio families were genotyped. Relative quantification of protein kinase $\mathrm{C}$, eta mRNA expression was performed from whole blood in 24 unrelated rheumatoid arthritis patients and in 16 healthy controls. Our results showed no significant associ-
\end{abstract}

V. H. Teixeira $\cdot$ L. Jacq $\cdot$ J. Moore $\cdot \mathrm{S}$. Lasbleiz $\cdot$ F. Cornelis $\cdot$

E. Petit-Teixeira

GenHotel-EA3886, Evry-Paris VII Universities,

Evry-Genopole, France

V. H. Teixeira

Faculty of Medicine, University of Coimbra,

Coimbra, Portugal

L. Jacq $\cdot$ P. Hilliquin $\cdot$ F. Cornelis

Centre Hospitalier Sud Francilien,

Corbeil-Essonnes, France

S. Lasbleiz

Service de Rhumatologie, Hôpital Lariboisière,

Paris, France

C. Resende Oliveira

Center for Neurosciences and Cell Biology, Faculty of Medicine,

University of Coimbra,

Coimbra, Portugal

F. Cornelis

Unité de Génétique Clinique, Hôpital Lariboisière,

Paris, France

V. H. Teixeira $(\bowtie)$

Genhotel-EA3886, Laboratoire Européen de Recherche

pour la Polyarthrite Rhumatoïde,

2 Rue Gaston Crémieux,

91057 Evry-Genopole Cedex, France

e-mail: vitor@polyarthrite.net ation or linkage between the protein kinase C, eta polymorphisms, and rheumatoid arthritis. The protein kinase $\mathrm{C}$, eta mRNA was expressed at lower level in rheumatoid arthritis unrelated patients than in healthy controls. This study shows that protein kinase $\mathrm{C}$, eta gene is not a Rheumatoid Arthritis major susceptibility genetic factor in the French Caucasian population. Furthermore, the lower expression of this gene in rheumatoid arthritis patients comparing to healthy controls suggests that protein kinase $\mathrm{C}$, eta could be associated with the patho-physiologic mechanism of rheumatoid arthritis.

Keywords $P R K C H$ gene - rheumatoid arthritis - association study $\cdot$ gene expression $\cdot$ single nucleotide polymorphism

\section{Introduction}

Rheumatoid Arthritis (RA) is a chronic inflammatory disease characterized by persistent joint synovial tissue inflammation associated with the destruction of affected joints [1]. During the RA development, autoreactive T cells are activated and recruited to joints mediating the synovial inflammation and finally causing tissue damage and cartilage and bone invasion [2]. Previous studies have shown that many autoreactive $\mathrm{T}$ cells, expressing high levels of CD45RO, are present in synovial fluid of RA patients [3] demonstrating that these autoreactive T cells are activated and have adopted an effector/memory phenotype [4]. Immunosuppressive drugs or anti-cell antibodies were used to eliminate or inhibit $\mathrm{T}$ cells causing an amelioration of the disease [5]. Hence, it is apparent that autoreactive $\mathrm{T}$ cells play important roles in synovial tissue inflammation in RA patients. The biologic mechanism of these autoreactive $\mathrm{T}$ cells in RA remains poorly studied. 
Protein kinase $\mathrm{C}$, eta $(P R K C H)$ gene, which encodes the $\eta$ isozyme of protein kinase $\mathrm{C}(\mathrm{PKC})$ ), is a good functional candidate for susceptibility to RA because protein kinase $\mathrm{C}$ (PKC) plays an important role in signal transduction controlling T-cell activation. The PKC gene family consists of more than 11 members, including $P R K C H / \mathrm{PKC} \eta$, and their individual products have been revealed to be involved in different cellular biological functions in various cell types [6]. Recent papers suggest that some isozymes of PKC are involved in critical functions of T cells [7, 8].

A previous study reported a significant association $(P<$ 0.05 ) for a landmark SNP (rs767755), located in intron 2 of the PRKCH gene, with RA in a case-control Japanese population. Subsequent analysis of additional single nucleotide polymorphisms (SNPs) within this gene revealed multiple SNPs located in three distinct linkage disequilibrium blocks to be significantly associated with RA. In each linkage disequilibrium block the most significant associated SNP was reported (+8134C/T, rs912620, and rs959728). Furthermore, they have shown that $P R K C H$ gene was expressed at high levels in resting $\mathrm{T}$ cells and this expression was downregulated by immune responses suggesting that $\mathrm{PKC} \eta$ is involved in signaling pathways to T cells [9].

In this study, we tested $P R K C H+8134 \mathrm{C} / \mathrm{T}$, rs912620, and rs959728 SNPs for RA association and linkage in 100 French Caucasian trios. Moreover, the level of expression of $P R K C H$ mRNA in 24 French Caucasian unrelated RA patients and in 16 French Caucasian healthy controls and the association between haplotypes of the SNPs tested and the level of expression in 24 unrelated RA patients were studied.

\section{Methods}

Patients and Healthy Controls

The study was approved by the Ethics Committees of Hôpital Bicêtre and Hôpital Saint Louis (Paris, France) and all subjects provided informed consent. One hundred RA trio families (one patient and both healthy parents) with the four grandparents of French Caucasian origin were recruited through a national media campaign. Characteristics of the RA trio families sample are reported in Table I.
Among the 24 French Caucasian unrelated RA patients, 18 were women (mean \pm SD age at enrolment 53.6 \pm 12.1 ). Depending on the swollen/tender joint count at the time of the study, there were 17 severe RA patients (minimum five inflamed joints) and seven mild RA patients (less than five active joints). All RA patients have received diseasemodifying anti-rheumatoid drugs (DMARDs) and corticosteroid therapy before the inclusion in the study. All RA patients satisfied the revised criteria of the American College of Rheumatology [10] according to the rheumatologist in charge of the patient. A rheumatologist university fellow reviewed all clinical data. Between the 16 French Caucasian healthy controls, 11 were women (mean $\pm \mathrm{SD}$ age at enrolment $47.8 \pm 7.5$ ).

\section{Molecular Genotyping Method}

Genomic DNA of the 100 French Caucasian RA trio families and the 24 French Caucasian unrelated RA patients was isolated and purified from fresh peripheral blood leukocytes according to standard protocols. Genotyping of the $P R K C H+8134 \mathrm{C} / \mathrm{T}$ polymorphism was performed by the polymerase chain reaction (PCR) followed by restriction fragment length polymorphism (PCR-RFLP) method [11]. The designed primers were: sense 5'ATGTGGTTTAT TATAGTATTCTACTTT3' and anti-sense $5^{\prime}$ TACTCACC TGTTCCTACCTGCA $3^{\prime}$. Primers were tested using the BLAST algorithm to ensure that only the $P R K C H$ gene was amplified. PCR amplification was performed on each sample in a $25-\mu 1$ reaction volume consisting of $10 \times$ PCR buffer (Perkin-Elmer, Boston, MA, USA), $1.25 \mathrm{mM}$ of each dNTP, $1.25 \mathrm{U}$ of Taq Gold DNA polymerase (PerkinElmer), $3 \mathrm{mM} \mathrm{MgCl} 2,0.0125 \mathrm{nM}$ of the two primers (Invitrogen, Cergy Pontoise, France) and 50 ng of genomic DNA, diluted to the final volume with $\mathrm{H}_{2} \mathrm{O}$ on Eppendorf thermocycler. The PCR program was carried out using the following amplification protocol: 37 cycles of denaturation at $96^{\circ} \mathrm{C}$ for $30 \mathrm{~s}$, with annealing temperature at $59^{\circ} \mathrm{C}$ for $30 \mathrm{~s}$ followed by an elongation step at $72^{\circ} \mathrm{C}$ for $1 \mathrm{~min}$. One final cycle of the extension was performed at $72^{\circ} \mathrm{C}$ for 10 min. A 360-bp amplified fragment was digested with NlaIII (Ozyme, Montigny Le Bretonneux, France) generat-
Table I Characteristics of Rheumatoid Arthritis (RA) index cases from the investigated sample

*DRB1*0101, DRB1*0102, $D R B 1 * 0401, D R B 1 * 0404$, $D R B 1 * 0405, D R B 1 * 0408$, $D R B 1 * 1001$.

\begin{tabular}{ll}
\hline & RA patients $(n=100)$ \\
\hline Females (\%) & 87 \\
Mean age ( \pm standard deviation, SD) at disease onset (years) & $32( \pm 10)$ \\
Mean ( \pm SD) disease duration (years) & $18( \pm 7)$ \\
RA patients with bone erosions (\%) & 90 \\
RA patients seropositive for rheumatoid factor (\%) & 81 \\
RA patients seropositive for anti-cycle citrullinated peptides antibodies $(\%)$ & 78 \\
RA patients carrying at least one $H L A-D R B$ lshared epitope allele $(\%)^{*}$ & 78 \\
\hline
\end{tabular}


ing two fragments (187 and $139 \mathrm{bp}$ ) when the restriction site located at the SNP locus was present ( $\mathrm{C}$ allele). Two independent investigators assessed genotypes blindly. Genotyping of the PRKCH rs912620 and rs959728 SNPs was carried out with a Taqman $5^{\prime}$ allelic discrimination assay on an ABI 7500 real-time PCR machine (assays: C_7600119_10, C_7600090_10, respectively; Applied Biosystems, Foster City, CA, USA). Allele-specific probes were labeled with the fluorescent dyes VIC and FAM. PCR reaction was carried out in a total volume of $15 \mu \mathrm{l}$ with the following amplification protocol: denaturation at $95^{\circ} \mathrm{C}$ for $10 \mathrm{~min}$, followed by 40 cycles of denaturation at $92^{\circ} \mathrm{C}$ for $15 \mathrm{~s}$, annealing and extension at $60^{\circ} \mathrm{C}$ for $1 \mathrm{~min}$. Genotyping of each sample was automatically attributed using the sodium dodecyl sulfate (SDS) software for allelic discrimination. Ten percent of the samples chosen at random were genotyped again for quality control.

PRKCH mRNA Expression by Real-Time Quantitative Reverse Transcription-PCR

Total RNA of the 24 French Caucasian unrelated RA patients and 16 French Caucasian healthy controls from whole blood was extracted using a PAXgene Blood RNA kit (Qiagen, Hilden, Germany). The measure of the RNAs concentration was performed using the RNA RiboGreen dye (Invitrogen). The integrity of the RNAs was analyzed using the Agilent 2100 Bionalyzer (Agilent, Santa Clara, CA, USA). Reverse-transcription was performed in a total volume of $20 \mu \mathrm{l}$ with SuperScript ${ }^{\mathrm{TM}}$ III First-Strand Synthesis SuperMix for qRT-PCR (Invitrogen) using $1 \mu \mathrm{g}$ of each total RNA and random hexamers according to the manufacturer's protocol. The kit includes RNaseOUT ${ }^{\mathrm{TM}}$ recombinant ribonuclease inhibitor as an RNase protector. Real-time quantitative reverse transcriptase PCR (RT-PCR) analysis was executed on an ABI Prism 7500 machine, using TaqMan Gene Expression Assays probes (Applied Biosystems) for PRKCH (Hs00178933_ml) and TaqMan Endogenous Controls probes (Applied Biosystems) for $A C T B$ ( $\beta$-actin), GAPDH (Glyceraldehyde-3-phosphate dehydrogenase) and $B 2 M(\beta-2-m i c r o g l o b u l i n)$. Each sample was tested in duplicate and a sample without template was included in each run as a negative control. The expression level of the PRKCH transcript was quantified using the threshold cycle $(\mathrm{Ct})$ method and normalized to the amount of $A C T B, G A P D H$, and B2M. Samples showing $\mathrm{Ct}$ values $>35$ and duplicates with a $\mathrm{Ct}>0.3$ were retested.

\section{Haplotype Assignment}

The $P R K C H$ gene haplotypes obtained taking into account the unphased SNP genotype data of the 24 unrelated RA patients was performed using fastPHASE 1.2 software [12].

\section{Statistical Analysis}

After the hypothesis of an RA association profile of $P R K C H$ in a French Caucasian population similar to that observed in Japanese RA patients, we used the reported allelic frequencies of the $P R K C H+8134 \mathrm{C} / \mathrm{T}$ SNP in Japanese RA patients (17\%) and in controls (22.2\%) [9]. Using the binomial distribution, we had $88.5 \%$ power to detect a trend in favor of an association: probability of having the frequency in patients superior to that in controls following the binomial distribution for $n$ observations $(0-100$ in our trio index) [13].

The Hardy-Weinberg equilibrium was checked in the control group (constituted by the nontransmitted parental chromosomes from trio) before analysis.

The linkage and association analysis relied on the Transmission disequilibrium test (TDT) [14], which compares, for a given allele, its transmission from heterozygous parents to RA patients, with the transmission expected from Mendel's law (i.e., 50\%). Secondly, we used the genotypes relative risk (GRR), which compares the affected offspring's genotype with the control genotype derived from nontransmitted parental chromosomes, using the method proposed by Lathrop [15]. Statistical significance was considered for $P<0.05$.

Results of relative mRNA expression are presented as the mean \pm standard deviation percentage. Statistical analysis of the relative expression of the $P R K C H$ in RA patients and healthy controls was performed using the MannWhitney test and $P<0.05$ was considered significant.

Table II Transmission Disequilibrium Test (TDT) for $P R K C H+8134 \mathrm{C} / \mathrm{T}$, rs912620, rs959728 SNPs, and RA (100 Trio families)

\begin{tabular}{|c|c|c|c|c|c|}
\hline$P R K C H$ SNPs & Allele & Transmitted & Nontransmitted & $T(\%)$ & $P$ value \\
\hline$+8134 \mathrm{C} / T$ & $C$ & 40 & 40 & 50 & 1 \\
\hline $\operatorname{rs} 912620(G>T)$ & $G$ & 42 & 46 & 47.7 & 0.67 \\
\hline rs959728 $(C>T)$ & $C$ & 17 & 22 & 43.6 & 0.42 \\
\hline
\end{tabular}

$T=$ Percentage of transmission from heterozygous parents 
Table III Genotype Relative Risk (GRR) for $P R K C H$ $+8134 \mathrm{C} / \mathrm{T}, \mathrm{rs} 912620$, rs 959728 SNPs, and RA (100 Trio families)

\begin{tabular}{llll}
\hline PRKCH SNPs & Genotypes & $\begin{array}{l}\text { Lathrop } P \text { value } \\
\text { (one genotype vs the others) }\end{array}$ & Global $P$ value \\
\hline$+8134 C / T$ & CC & 0.63 & 1 \\
& CT & & \\
rs912620 $(G>T)$ & TT & 0.44 & 0.90 \\
& GG & 0.46 & \\
rs959728 $(C>T)$ & GT & & 0.61 \\
& TT & 0.89 & \\
& CC & 0.28 & \\
& TT & 0.58 & \\
\hline
\end{tabular}

The association between haplotypes of the SNPs tested and the level of expression in 24 unrelated RA patients was assessed by the Mann-Whitney test. Data are expressed as the mean \pm standard deviation and $P<0.05$ was considered significant.

\section{Results}

Hardy-Weinberg Equilibrium Check

The $P R K C H+8134 \mathrm{C} / \mathrm{T}$, rs912620 and rs959728 SNPs were in Hardy-Weinberg equilibrium in the control sample investigated.

Test for Linkage and Association in the Trio RA Families

We test the $P R K C H$ putative susceptibility alleles $+8134 \mathrm{C}$, rs912620-T and rs959728-T for which association with RA was the most significant in the case-control Japanese population [9].

We did not observe a linkage and association between the $+8134 \mathrm{C}$ allele and RA: there was an equal transmis- sion of $+8134 \mathrm{C}$ allele and $+8134 \mathrm{~T}$ allele from heterozygous parents (40 transmitted $v s .40$ nontransmitted, $P=1$ ) (Table II). There was no significant overtransmission of the rs912620-T allele from heterozygous parents (46 transmitted vs. 42 nontransmitted, $P=0.67$ ) (Table II). The same result is observed for the rs959728-C allele (22 transmitted vs. 17 nontransmitted, $P=0.42$ ) (Table II). The GRR analysis of the $P R K C H+8134 \mathrm{C} / \mathrm{T}$, rs912620, and rs959728 SNPs showed no significant $(P>0.05)$ association of the homozygous or heterozygous genotypes for susceptibility alleles with RA (Table III). The TDT analysis of PRKCH +8134C/T-rs912620-rs959728 haplotypes did not reveal any significant association for the seven haplotypes estimated (data not shown).

\section{Expression Analysis}

A relative quantification of $\mathrm{PRKCH}$ mRNA expression was performed in total RNA from whole blood in 24 unrelated RA patients and in 16 healthy controls. $P R K C H$ was expressed in RA patients at lower level $(-92 \% ; P<$ 0.0001 ) than in healthy controls (Fig. 1). Figure 2 reported the relative quantification of $P R K C H$ mRNA in severe and

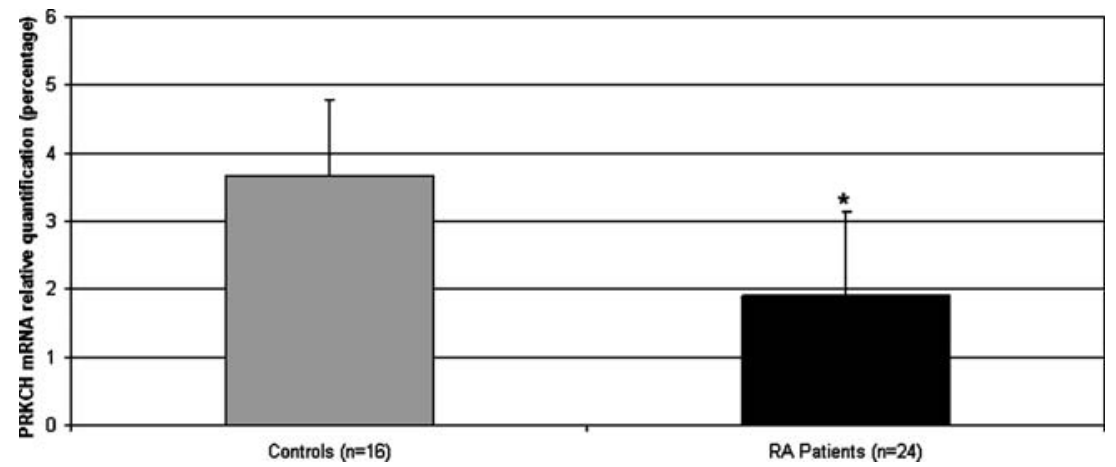

Fig. 1 Levels of $P R K C H$ mRNA expression in peripheral blood from RA unrelated patients and healthy controls. $P R K C H$ mRNA levels were determined by real-time quantitative RT-PCR and normalized to $A C T B, G A P H D$, and B2M levels. The expression level of the PRKCH

transcript was quantified using the threshold cycle $(\mathrm{Ct})$ method. Data are presented as the mean $\pm \mathrm{SD}$ percentage of the $P R K C H$ mRNA expression. ${ }^{*} P<0.0001$ versus Controls, by Mann-Whitney test. 


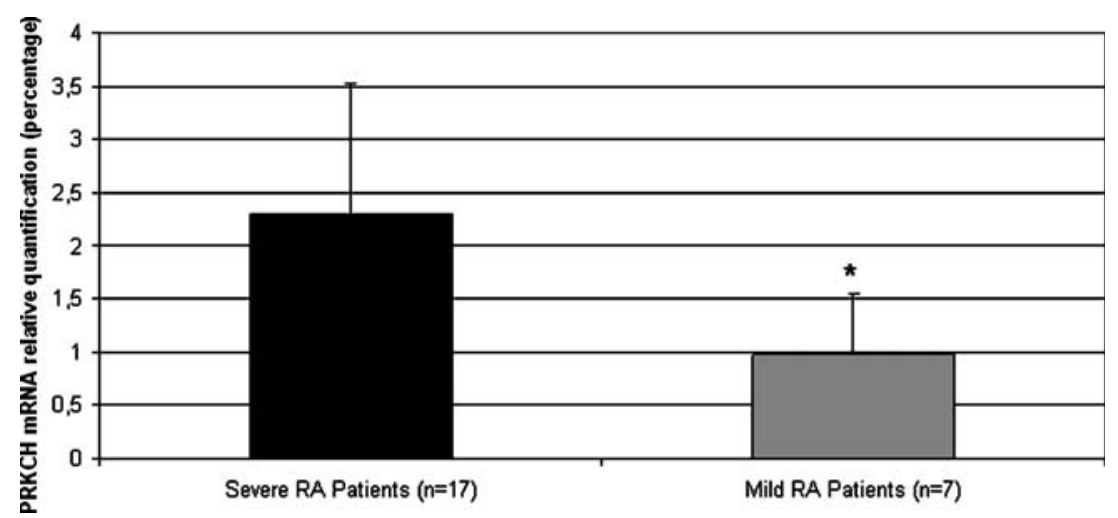

Fig. 2 Levels of $P R K C H$ mRNA expression in peripheral blood from severe and mild RA patients. $P R K C H$ mRNA levels were determined by real-time quantitative RT-PCR and normalized to $A C T B, G A P H D$, and $B 2 M$ levels. The expression level of the $P R K C H$ transcript was

mild RA patients. The expression of $P R K C H$ in severe RA patients was higher than in mild RA patients $(P=0.008)$.

We selected three haplotype combinations: CTT/CTT (haplotype homozygous for the susceptible alleles), CTT/X (haplotype heterozygous for the susceptible alleles), and $\mathrm{X} / \mathrm{X}$ (haplotype with no susceptible alleles). In the set of 24 unrelated RA patients, there were four RA patients with $\mathrm{CTT} / \mathrm{X}$ haplotype, 20 with $\mathrm{X} / \mathrm{X}$ and no one with $\mathrm{CTT} / \mathrm{CTT}$. Although the expression of $P R K C H$ mRNA was lower in RA patients with $\mathrm{CTT} / \mathrm{X}$ haplotype compared to $\mathrm{X} / \mathrm{X}$ haplotype (Fig. 3), we did not observe a significant association $(P=0.94)$.

\section{Discussion}

This study was designed to test the PRKCH $+8134 \mathrm{C} / \mathrm{T}$, rs912620 and rs959728 SNPs for linkage to, and association with, RA in a French Caucasian familial population. In quantified using the threshold cycle $(\mathrm{Ct})$ method. Data are presented as the mean \pm SD percentage of the $P R K C H$ mRNA expression. $* P=0.008$ versus severe RA patients, by Mann-Whitney test.

addition, we studied the level of expression of $P R K C H$ mRNA in RA patients and in healthy controls and the association between haplotypes of the SNPs tested and the level of expression in RA patients.

Takata et al. [9] described the $+8134 \mathrm{C}$, rs $912620-\mathrm{T}$, and rs959728-T alleles from SNPs located in three different linkage disequilibrium blocks susceptible for RA. We have confirmed that these susceptibility alleles were not in linkage disequilibrium in the French Caucasian population (data not shown). In the linkage disequilibrium block D described by Takata et al. [9], we have chosen to test the rs959728 SNP, which is more associated to RA than rs2230500 SNP ( $P=0.00011$ vs $P=0.0016)$. This functional SNP rs2230500 located in exon 9 (V3741I) was reported to increase the risk of cerebral infarction [16]. Our results showed a clear absence of RA linkage and association in the population investigated for the three SNPs tested. In good agreement with the TDT analysis, the GRR revealed a lack of association between the different genotypes and RA.

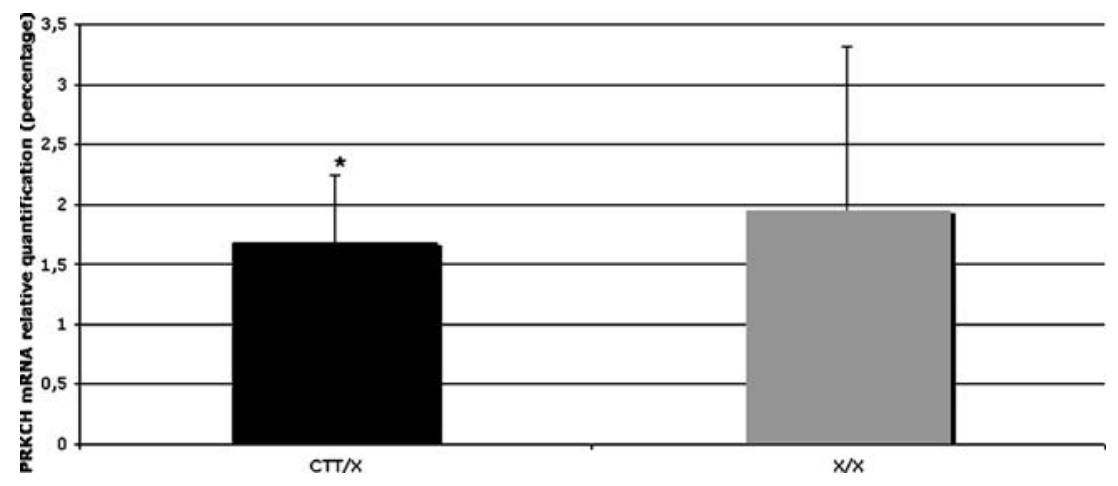

Fig. 3 Association between the level of $P R K C H$ mRNA expression and $P R K C H$ haplotype (+8134C/T-rs912620-rs95972824) in RA patients. $P R K C H$ mRNA levels were determined by real-time quantitative RT-PCR and normalized to $A C T B, G A P H D$, and $B 2 M$ levels. The expression level of the $P R K C H$ transcript was quantified using the threshold cycle $(\mathrm{Ct})$ method. Four samples in the CTT/X haplotypes and 20 in the $\mathrm{X} / \mathrm{X}$ haplotypes were analyzed. Data are presented as the mean $\pm \mathrm{SD}$ percentage of the $P R K C H$ mRNA expression. ${ }^{*} P=0.94$ versus $\mathrm{X} / \mathrm{X}$ haplotypes, by Mann-Whitney test. 
The linkage analysis of PRKCH +8134C/T-rs912620 rs959728 haplotypes was not significant as none of the seven haplotypes described were overtransmitted (data not shown). The results were obtained with a particularly robust method, the Transmission Disequilibrium Test [14], which compares, for a given allele, its transmission from heterozygous parents to RA patients, with the transmission expected from Mendel's law (i.e., 50\%). This family-based analysis avoids imperfect population match between patients and controls and permits the direct test of the Mendel's law. These results allowed us to exclude $P R K C H$ as a major significant genetic factor in RA in a French Caucasian population. There were several genetic studies that reported differences in ethnic variations of polymorphisms associated with RA as PADI4 and SLC22A4 genes [17-19]. Moreover, PRKCH locus was not included among the suggested 19 non-HLA regions in the French Caucasian population [20]. The last genome-wide association study in a UK Caucasian population had found 9 SNPs that map to loci not associated previously to RA [21]. However, $P R K C H$ locus was not present in these regions. Thus, other populations need to be studied to define extensively the involvement of this gene in the genetics of RA.

Even some PKC isozymes have been suggested to be involved in important functions of $\mathrm{T}$ cells $[7,8]$ the physiological function of PKC $\eta$ in $\mathrm{T}$ cells has not yet been well documented and the pathway by which PRKCH SNPs may influence RA risk remains unknown.

This study is the first to show that $P R K C H$ was expressed in RA patients at a lower level than in non-RA controls in peripheral blood cells. This result suggests that expression of the $P R K C H$ gene is regulated through immune responses. This observation confirms the study of Takata et al. [9] who have shown that $P R K C H$ gene is expressed in resting CD4+ cells (T helper/inducer cells) or CD8+ cells (T suppressor/ cytotoxic cells) at higher levels than in resting CD19+ cells (B cells) or CD14+ cells (monocytes) and the expression in these cells were significantly downregulated by activation.

Our data also show the PRKCH mRNA highly expressed in severe RA patients comparing to mild RA patients, supporting the increase of expression of $P R K C H$ during the progression of the disease from mild to severe RA. PKCn functions have been associated to the cytokine signaling cascade in monocytes and macrophages. Indeed, plasma levels of nitric oxide, a mediator of inflammation, were shown to be elevated in patients with severe RA, and a positive association between $P R K C H$ and inducible nitric oxide synthase (iNOS) expression was observed in peripheral blood monocyte-derived macrophages from severe RA patients. Furthermore, this coexpression was not present in healthy controls [22].

Heale et al. [23] have confirmed these results reporting a $\mathrm{PKC} \eta$-expression phenotype in monocytes for mild and severe RA patients and not for healthy controls. Moreover, there was a progressive and concordant expression of $\mathrm{PKC} \eta$ and iNOS phenotypes in monocytes from RA patients associated with the severity of the disease.

These studies provided evidence supporting the possible involvement of $\mathrm{PKC \eta}$ in immunologic activities of T cells, monocytes and macrophages, whereas our study highlighted an overall expression of $P R K C H$ gene in whole blood from RA patients. The association of $P R K C H$ differential expression and the patho-physiologic mechanism in RA should be then further investigated.

The relation between haplotypes and expression level of $P R K C H$ gene was not identified, as the expression of $P R K C H$ mRNA was lower in RA patients with $\mathrm{CTT} / \mathrm{X}$ haplotype comparing to $\mathrm{X} / \mathrm{X}$ haplotype but without significance. Nevertheless, the determination of haplotype effects should require an extensive examination of expression in different cell subsets and RA states.

\section{Conclusions}

We provided evidence against the involvement of the $P R K C H$ gene in the genetics of RA in a French Caucasian familial population. However, replication studies in other independent Caucasian populations are required to confirm these results. Our study is the first to show that PRKCH was expressed in RA patients at lower level than in non-RA controls in peripheral blood cells. Further investigations in the regulation of $P R K C H$ expression in RA are necessary to prove the involvement of $\mathrm{PKC} \eta$ molecular mechanisms in disease susceptibility, more specifically in signaling pathways of RA-specific immune response.

Acknowledgments This work was supported by AFSSAPS, Association Française des Polyarthritiques, Société Française de Rhumatologie, Association Rhumatisme et Travail, Association Polyarctique, Groupe Taitbout, Genopole ${ }^{\circledR}$, Conseil Régional Ile de France, Fondation pour la Recherche Médicale, Université Evry-Val d'Essonne and unrestricted institutional support from Wyeth, ScheringPlough, Pfizer, and Amgen. Vitor Hugo Teixeira's work was supported by Foundation for Science and Technology, Portugal (grant $\mathrm{SFRH} / \mathrm{BD} / 23304 / 2005$ ). We are grateful to the RA patients, their families, and rheumatologists for participation in this study. We thank Dr Robert Olaso (Centre National de Génotypage, France), Fréderique Bitton, Samuel Mainguet, Dr Fabiana Heredia, and Filipe Teixeira (French National Institute for Agricultural Research, France).

\section{References}

1. Seldin MF, Amos CI, Ward R, Gregersen PK. The genetics revolution and the assault on rheumatoid arthritis (review). Arthritis Rheum 1999;42:1071-79. 
2. Panayi GS, Lanchbury JS, Kingsley GH. The importance of the T cell in initiating and maintaining the chronic synovitis of rheumatoid arthritis. Arthritis Rheum 1992;35:729-35.

3. Thomas R, Mcllraith M, Davis LS, Lipsky PE. Rheumatoid synovium is enriched in CD45RBdim mature memory $\mathrm{T}$ cells that are potent helpers for B cell differentiation. Arthritis Rheum 1992;35:1455-65.

4. Sallusto F, Geginat J, Lanzavecchia A. Central memory and effector memory $\mathrm{T}$ cell subsets: function, generation and maintenance. Annu Rev Immunol 2004;22:745-63.

5. Mima T, Saeki Y, Ohshima S, Nishimoto N, Matsushita M, Shimizu $\mathrm{M}$ et al. Transfer of rheumatoid arthritis into severe combined immunodeficient mice. J Clin Invest 1995;96:1746-58.

6. Dempsey EC, Newton AC, Mochly-Rosen D, Fields AP, Reyland $\mathrm{ME}$, Insel PA et al. Protein kinase $\mathrm{C}$ isozymes and the regulation of diverse cell responses. Am J Physiol Lung Cell Mol Physiol 2000;279:429-38.

7. Baier G. The PKC gene module: molecular biosystematics to resolve its T cell functions. Immunol Rev 2003;192:64-79.

8. Volkov Y, Long A, McGrath S, Ni Eidhin D, Kelleher D. Crucial importance of PKC- $\beta(\mathrm{I})$ in LFA-1-mediated locomotion of activated T cells. Nat Immunol 2001;2:508-14.

9. Takata Y, Hamada D, Miyatake K, Nakano S, Shinomiya F, Scafe $\mathrm{CR}$ et al. Genetic association between the $P R K C H$ gene encoding protein kinase $\mathrm{C}$ isozyme and rheumatoid arthritis in the Japanese population. Arthritis Rheum 2007;56:30-42.

10. Arnett FC, Edworthy SM, Bloch DA, McShane DJ, Fries JF, Cooper NS et al. The American Rheumatism Association 1987 revised criteria for the classification of rheumatoid arthritis. Arthritis Rheum 1988;31:315-24.

11. Botstein D, White RL, Skolnick M, Davis RW. Construction of a genetic linkage map in man using restriction fragment length polymorphisms. Am J Hum Genet 1980;32:314-31.

12. Scheet P, Stephens MA. Fast and flexible statistical model for large-scale population genotype data: applications to inferring missing genotypes and haplotypic phase. Am J Hum Genet 2006;78(4):629-44.

13. Garnier S, Dieudé P, Michou L, Barbet S, Tan A, Lasbleiz S et al. IRF5 rs2004640-T allele, the new genetic factor for systemic lupus erythematosus, is not associated with rheumatoid arthritis. Ann Rheum Dis 2007;66:828-31.

14. Spielman R, McGinnis E, Ewens W. Transmission test for linkage disequilibrium: the insulin gene region and insulin-dependent diabetes mellitus (IDDM). Am J Hum Genet 1993;52:506-26.

15. Lathrop GM. Estimating genotype relative risks. Tissue Antigens 1983;22(2):160-6.

16. Kubo M, Hata J, Ninomiya T, Matsuda K, Yonemoto K, Nakano T et al. A nonsynonymous SNP in PRKCH (protein kinase $\eta$ ) increases the risk of cerebral infarction. Nat Genet 2007;39(2):212-7.

17. Caponi L, Petit-Teixeira E, Sebbag M, Bongiorni F, Moscato S, Pratesi $\mathrm{F}$ et al. A family based study shows no association between rheumatoid arthritis and the PADI4 gene in a white French population. Ann Rheum Dis 2005;64(4):587-93.

18. Tokuhiro S, Yamada R, Chang X, Suzuki A, Kochi Y, Sawada T et al. An intronic SNP in a RUNX1 binding site of SLC22A4, encoding an organic cation transporter, is associated with rheumatoid arthritis. Nat Genet 2003;35:341-8.

19. Barton A, Eyre S, Bowes J, Ho P, John S, Worthington J. Investigation of the SLC22A4 gene (associated with rheumatoid arthritis in a Japanese population) in a United Kingdom population of rheumatoid arthritis patients. Arthritis Rheum 2005;52(3):752-8.

20. Osorio Y, Fortéa J, Bukulmez H, Petit-Teixeira E, Michou L, Pierlot $\mathrm{C}$ et al. Dense genome-wide linkage analysis of rheumatoid arthritis including covariates. Arthritis Rheum 2004;50:2757-65.

21. The Wellcome Trust Case Control Consortium: Genome-wide association study of 14,000 cases of seven common diseases and 3,000 shared controls. Nature 2007;447:661-78.

22. Pham T, Rahman P, Tobin, Khraishi M, Hamilton S, Alderdice C et al. Elevated serum nitric oxide levels in patients with inflammatory arthritis associated with co-expression of inducible nitric oxide synthase and protein kinase $c-\eta$ in peripheral blood monocytes-derived macrophages. J Rheumatol 2003;30(12): 2529-34.

23. Heale E, Fahraeus-Van Ree E, Rahman P, Richardson J. Progressive and concordant expression of PKC-eta and iNOS phenotypes in monocytes from patients with rheumatoid arthritis: association with disease severity. J Histochem Cytochem 2007;55 (5):495-503. 